\title{
LEARNING DELIVERY MODALITIES AND ACADEMIC PERFORMANCE AT THIS TIME OF PANDEMIC AMONG SELECTED PSYCHOLOGY STUDENTS OF ST. DOMINIC COLLEGE OF ASIA: A COMPARATIVE STUDY
}

\author{
Philip Cordova Cuizon \\ Prof. Dr., St. Dominic College of Asia, Philippines, pcuizon@sdca.edu.ph
}

\begin{abstract}
This study aimed to determine the academic performance of selected Psychology students of St. Dominic College of Asia based on the learning modalities deployed during lockdown period due to Covid-19 Pandemic. A total of 50 respondents participated in this study. Based on academic practice, the institution has 3 academic periods such as Prelim, Midterm and Final Period. Prelim period deployed full Face-to-Face Learning Modality while Midterm Period used a Blended Learning Modality which is a combination of Faceto-Face Learning Modality and Online Learning Modality. Weighted average per period was used as basis in the Academic Performance. Results showed that a Blended Learning Modality and Full Online Learning Modality is significantly higher in terms of weighted average than Face-to-Face Learning Modality. It also resulted that demographic profiles such as sex(female), number of units and subjects enrolled has nothing to do with academic performance across all types of learning modalities. Lower year levels significantly performed better than higher year level across all types of learning modalities.
\end{abstract}

Keywords: Academic Period, Face-to-Face Learning Modality, Blended Learning Modality, Full Online Learning Modality, Academic Performance.

\section{INTRODUCTION}

Covid-19 is a current global concern that each country is striving to face it. The said concern is a classified as a global Pandemic in which all areas of economics and organizations were affected at different level of severity. Until now, health protocols and medical interventions frontline solutions in each country. But the said solution is not sustainable since there is a need for innovations and medical advancements in order to combat this Pandemic.

Academic or educational institution is one of the severely affected by this pandemic. According to an article entitled "1 Pandemic school closures: risks and opportunities" published last May of 2020; school closures were reported across 188 countries. Here in the Philippines, based on the article published by ${ }^{2} \mathrm{CNN}$ Philippines last September 9, 2020, there were 748 private schools who suspended their operations due to Pandemic. This suspension of classes severely affected 3,233 teachers and 40,345 learners. To survive the academic operations of any academic institution at this time of crisis, schools deployed an online learning modality so as that students can still enrol and take online classes and there will still be jobs available for teachers.

Face-to-Face Learning Modality is a traditional set-up of class learning wherein students and teachers are in a room physically doing some discussions and interactions. Through class lectures, the context of the topic 
or subject is directly delivered, and students are getting involved in the teaching-learning process. Activities in the classroom can served not just a learning experience but also a socialization for students.

${ }^{3}$ Face-to-Face Learning Modality has advantages and disadvantages. The advantages of the said learning modality is that the lecturer supplies important supplementary notes that are essential for you to pass the exam, sharing and comparing of notes can be done by the classmates, questions are answered in real time which means that there is no need for you to wait for some time to receive a feedback or response, and assignments are handed personally which means that there is no need for you to worry on what school should be done at home. However, there are some disadvantages such as the lecturer has limited time in the class, not all questions can be entertained by the teacher during the class period, cost in terms of travelling to school back and forth, class schedule variations including idle periods between class schedules.

According to the study conducted by ${ }^{4} \mathrm{Kemp} \&$ Grieve (2014), there is an online preference in completing activities by the students however performance between traditional and online learning is not significantly different. Their study concluded that face-to-face and online learning modality is at a similar level in terms of academic performance. Discussion is being done face-to-face as and written activities are being done online as a preference. ${ }^{5}$ Carini et al., in 2006 stressed out that there is a positive association between student engagement in face-to-face class and performance in academics.

Blended learning modality or the combination of face-to-face classes and online classes is also being used by some colleges and universities across the globe. Students exposure to different learning modalities can help them to become flexible in learning activities of the education. ${ }^{6}$ The combination of face-to-face and online learning modality which is called blended learning is becoming more known in education sections and it is a trend in higher academic institution that is being accepted by teachers and professors (Bonk.et.al., 2006). ${ }^{7}$ In Blended learning, students are meeting face-to-face through synchronous communication and interact online as well. It is most commonly a combination of face-to-face learning and internet-based learning (Oliver \& Trigwell, 2005). ${ }^{8}$ According to Osguthorpe \& Graham (2003), the primary objective of blended learning is to find a balance between online learning access and physical interaction of students through face-to face learning. It is a mic of online and face-to-face activities that has a number of goals, knowledge access and interaction to both social environments.

Online Learning Modality is the most acceptable learning and teaching strategy at this time of Pandemic of crisis. Across the globe, in order for academe to continue its operations, they need to be strategic in the learning delivery by means of online. ${ }^{9}$ According to Alismail (2015), technology e-learning is a powerful tool that can access information and knowledge directly by the students and it can lead to learning independence as well. It is also a considerable role that teachers play a responsibility to guide the online engagement of students. Through online, there is an easy access with education data and information that is important in the academic success of students. ${ }^{10}$ According to Ituma in 2011 , online learning contributes to the substantial academic experience of students in universities in variety of countries. However, there is an increase in incorporating online session to face-to face classes in which traditional classes are replace with online activities.

${ }^{11}$ Chen et al., (2010) stressed that there is an increase engagement and learning among students in their participation in technology learning. Technology is needed so that online engagement of students is possible and reachable. ${ }^{12}$ There is better performance when students access materials online via interactive and navigated webpages (Evans et al., 2004).

Time is very important in learning. In online, through asynchronous activities, students have more time to accomplished and develop productive outputs due to considerable time given for accomplishing them. ${ }^{13}$ Flexibility on time allows students to be more critical and reflective in online activities which can lead to indepth understanding of the content of course (Robinson and Hullinger, 2008). Motivation plays an outgrowth role of online learning. ${ }^{14}$ The study of Salamat et.al., (2018) concluded that online learning provides flexibility in time and motivation to students. They can work independently without the assistance of others. Students are comfortable when they use internet.

Collaboration is also one of the activities being observed in an online learning. ${ }^{15}$ There is an improve collaborative process in small group learning in an online environment. There is a positive experience in online meeting were sharing of data, resources, and fieldwork are being done (Baskin, 2001). ${ }^{16}$ In the study of Stacey (1999), results shows that students learning online was enhanced through online collaborations as part of collaborative distance education of students.

Online learning modalities proves that students can achieve positive academic success in the absence of physical or face-to-face learning. ${ }^{17}$ According to the study initiated by Alducin-Ochoa \& Vazquez-Martinez 
(2016). Results shows that blended learning model of learning modality has more academic success than face-to-face or traditional learning modality. ${ }^{18}$ The study of Ladyshewsky (2004) proves that students in online learning is better than those who are on Face-to-Face learning. This is study based on his comparison among students taking graduate degree in business.

However, online education is not always a success to students. ${ }^{19}$ In the study of Davies and Graff in 2005 concluded that the participation and interaction of students in online learning did not resulted significantly better performance in academic than those students who participated less in online learning. ${ }^{20}$ It is supported in the study of Holley and Oliver (2010) that if students start with insufficiency in knowledge and support in technology, they feel discourage by the expectations of online study.

${ }^{21}$ The study of Helms in 2014 found out that students who are in online learning modality significantly had lower grades missed more academic opportunities and more likely to fall compared with students who are in traditional or face-to-face learning modality. ${ }^{20}$ Due to some technological constraints and previously taken instructional approaches, initial e-learning experiences failed to live with students or learner's expectations (Imel, 2002). ${ }^{21}$ Comparing face-to-face and online learning modality, students felt more disconnections from lecturers and classmates and are obliged to do self-directed learning in online (Otter et al., 2013).

${ }^{24}$ Student performance between face-to-face learning modality and online learning modality is not significantly difference. It also resulted that gender has nothing to do with performance of online and Face-toface learning (Paul, Jasmine et.al., 2019). ${ }^{25}$ In the study conducted by Sussman \& Dutter (2010), there was no difference found between face-to-face learning modality and full online course in the final grades based on GPA.

${ }^{26}$ The study conducted by Van Schaik et.al. (2003) found out that there is no significant difference between Face-to-Face and Online Learning Modality either test results or attrition rates. Similarly, ${ }^{27}$ the study conducted by Chen and Zimitat (2004) concluded that Face-to-Face and Online Learning Modality has no significant difference in student outcomes through test scores.

With these literatures this study focused on getting the weighted averages or grades of each student per academic period such as prelim, midterm and finals. Prelim period deployed a Face-to Face Learning modality. Midterm period deployed Blended Learning Modality which is a combination of Face-to Face Learning Modality and Online Learning Modality. Final period used Full-Online Learning Modality. In online learning modality, leniency is observed or students are given ample time to accomplish activities and examinations online asynchronously or at their own pace. These different learning modalities were deployed due to the community quarantine brought by Covid-19 Pandemic.

\section{METHODOLOGY}

\subsection{Participants}

Based on the compliance of officially enrolled students during second semester (January to May of 2020) of academic year 2019-2020, only 50 Psychology students were qualified to be the respondents of the study where in 11 were male psychology students and 39 female psychology students. Compliance means that all subjects enrolled during that term have a corresponding weighted average per period (Prelim, Midterm, and Finals).

This study utilized the academic grades of respondents for prelim, midterm, and finals. Face-to-face learning modality was used during prelim period, blended learning modality which is a combination of face-to-face and online learning was used during midterm period, and full online learning modality was used during final period. Each period has 5 weeks.

Respondents were profiled based on (a) sex (male, female), (b) number of units enrolled (above 20 and below 20 units), (c) year level (first year, second year and fourth year level), and (d) number of subjects enrolled during the term (less than 6 subjects, 6 to 7 subjects and more than 7 subjects).

\subsection{Computation of Average}

This study utilized the academic grades of respondents for prelim, midterm, and finals. Face-to-Face Learning Modality was used during prelim period, Blended Learning Modality which is a combination of Face-to-Face and Online Learning Modality was used during midterm period, and Full Online Learning Modality was used during final period. Each period has 5 weeks. Below is a sample computation of weighted average: 
Proceedings of INTCESS 2021 8th International Conference on Education and Education of Social Sciences 18-19 January, 2021

\begin{tabular}{|c|c|c|c|c|c|c|c|}
\hline & Units & \multicolumn{2}{|c|}{ Prelim Period } & \multicolumn{2}{c|}{ Midterm Period } & \multicolumn{2}{c|}{ Final Period } \\
\hline Subject 1 & 3 & 88.10 & 264.30 & 93.63 & 280.89 & 86.75 & 260.25 \\
\hline Subject 2 & 3 & 81.00 & 243.00 & 88.00 & 264.00 & 91.00 & 273.00 \\
\hline Subject 3 & 3 & 85.00 & 255.00 & 91.00 & 273.00 & 91.00 & 273.00 \\
\hline Subject 4 & 3 & 89.60 & 268.80 & 94.58 & 283.74 & 94.09 & 282.27 \\
\hline Subject 5 & 5 & 82.52 & 412.60 & 87.84 & 439.20 & 86.93 & 434.65 \\
\hline Subject 6 & 2 & 80.00 & 160.00 & 80.00 & 160.00 & 80.00 & 160.00 \\
\hline Subject 7 & 3 & 88.50 & 265.50 & 94.00 & 282.00 & 89.50 & 268.50 \\
\hline Subject 8 & 3 & 88.71 & 266.13 & 95.00 & 285.00 & 98.00 & 294.00 \\
\hline Total & 25 & & 2135.33 & & 2267.83 & & 2245.67 \\
\hline Average & & & 85.41 & & 90.71 & & 89.83 \\
\hline
\end{tabular}

The computation of their per period grade is based on the grade of the subject multiplied by the corresponding units per subject. Weighted average was used to get the performance of each student per period (prelim, midterm, and finals). Averages were collated and underwent statistical analysis.

\subsection{Statistical Analysis}

This study used within groups and between group analysis. Within group analysis is to check if there is statistical significance across three types of learning modalities (Face-to-Face, Blended, and Full Online) per sub-level of the demographic profile. The between group analysis is to check if there is statistical significance between sub-level (et.al. male vs female on Face-to-Face Learning Modality).

T-Test for Independent Samples was used to check for significant difference between two groups and OneWay Analysis of Variance was used to check for significant difference for more than two groups. Weighted Mean was also use to compute the average of respondents for each period (Prelim, Midterm, and Finals).

\section{RESULTS}

\subsection{Descriptive Results}

Table 1. Average Grade Per Demographic Profile

\begin{tabular}{|c|c|c|c|c|}
\hline \multicolumn{2}{|c|}{ Demographic Profile } & Prelim & Midterm & Finals \\
\hline \multirow{2}{*}{ Sex } & Male & 83.76 & 88.18 & 88.70 \\
\cline { 2 - 5 } & Female & 86.36 & 90.59 & 90.70 \\
\hline \multirow{3}{*}{ Number of Units } & Above 20 & 86.78 & 90.17 & 90.16 \\
\cline { 2 - 5 } & Below 20 & 84.42 & 89.92 & 90.39 \\
\hline \multirow{3}{*}{ Year Level } & Fourth & 82.55 & 87.86 & 88.39 \\
\cline { 2 - 5 } & Second & 87.43 & 92.34 & 92.85 \\
\cline { 2 - 5 } & First & 88.25 & 91.06 & 90.72 \\
\hline
\end{tabular}




\begin{tabular}{|l|c|c|c|c|}
\multirow{3}{*}{ Number of Subjects } & More than 7 & 87.14 & 90.35 & 89.99 \\
\cline { 2 - 5 } & 6 to 7 & 85.32 & 89.96 & 90.66 \\
\cline { 2 - 5 } & Less than 6 & 84.19 & 89.71 & 90.18 \\
\hline
\end{tabular}

Table above shows the average of students per demographic profile for each period (prelim, midterm and finals). Final period which is Face-to-Face Learning Modality obtained the highest average in both male and female respondents, Second Year and Fourth Year level, and less than 6 subjects. Midterm period which is a combination of Face-to-Face Learning Modality and Full Online Learning Modality obtained as the highest average in below and above 20 units, first year level and 6 or more subjects. However, Prelim period which is a Face-to-Face Learning Modality obtained the lowest average across sub-levels of demographic profiles.

\subsection{Within Group Results}

Table 2. Test for Significant Difference Within Groups

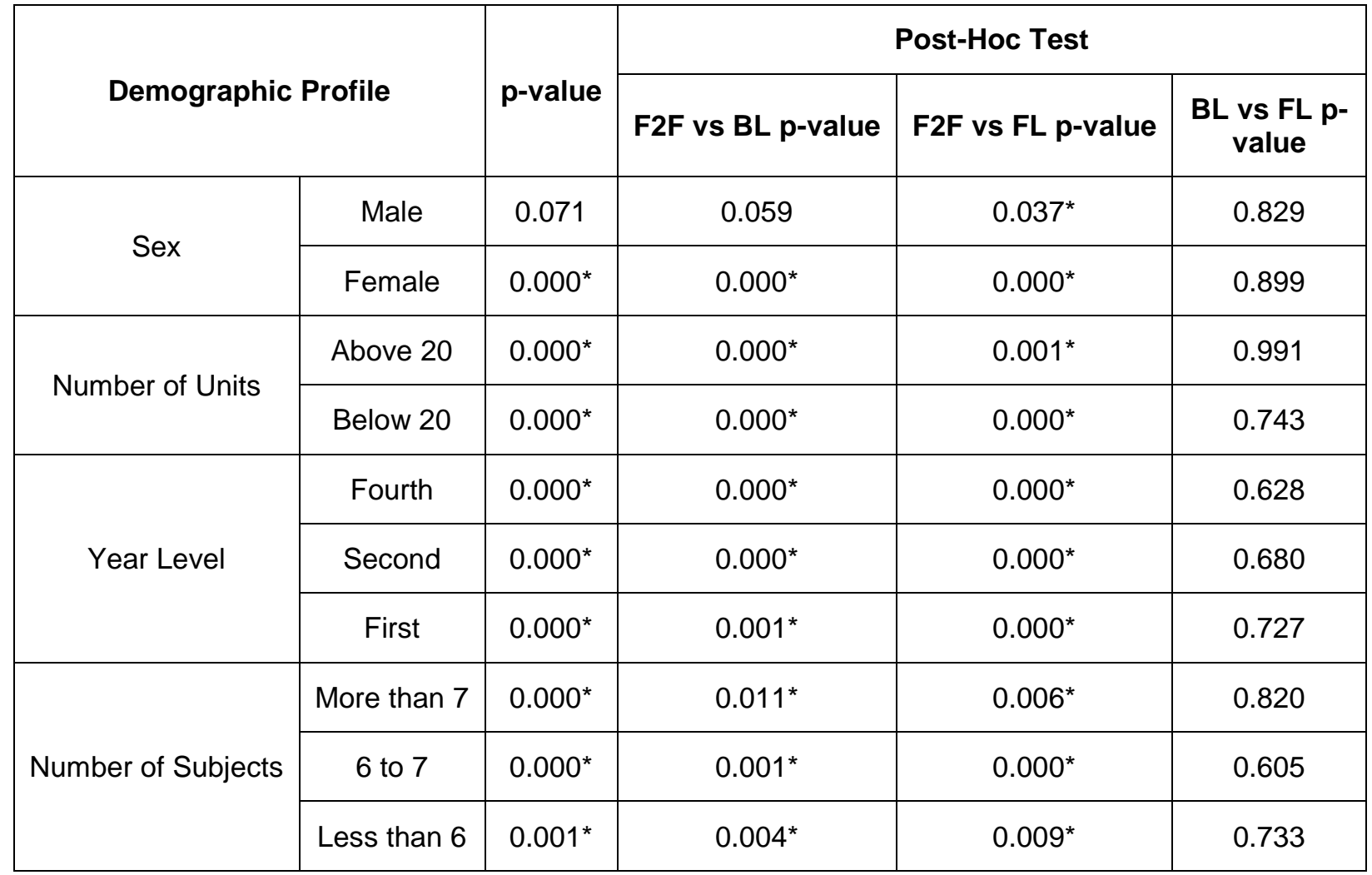

*Significant at .05 alpha level

$F 2 F=$ Face-to-Face; $B L=$ Blended Learning, $F L=$ Full Online

Table above shows the test of significant within group per demographic profile. This would mean that each sublevel of each demographic profile was statistically analysed to check if there is a significant difference in averages when different learning modalities were used.

For male respondents, the computed p-value when Face-to-Face learning modality is compared with Blended Learning Modality is not significant since the computed p-value is greater than .05 alpha level. The same results when Blended Learning Modality is compared with Full Online Learning. This would mean that there is no significant differences in averages when Face-to-Face Learning Modality is compared with Blended Learning and when Blended Learning Modality is compared with Full Online for male respondents.

However, the computed p-value when Face-to-Face Learning Modality is compared with Full Online Learning Modality is less than .05 alpha level. This would mean that there is significant difference in the averages. Hence, for male respondents, the average of Full Online Learning Modality is significantly higher than Face-to-Face Learning Modality 
For female respondents and other demographic profile such as Number of Units (Above 20 and Below 20), Year Level (First, Second, and Fourth), and number of subjects (more than 7 subjects, 6 to 7 subjects and less than 6 subjects), the computed p-value for Face-to-Face Learning Modality compared with Blended Learning Modality and Full Online Learning Modality is less than .05 alpha level. This would mean that difference in averages is significant. Hence, the weighted average of Blended Learning Modality and Full Online Learning Modality is significantly higher than Face-to-Face Learning Modality.

Across demographic profiles with their sub-level, the computed $p$-value is greater than .05 alpha level when Blended Learning Modality is compared with Full Online Learning Modality. This would mean that there is no significant difference in the averages between Blended Learning Modality and Full Online Learning Modality.

\subsection{Between Group Results}

Table 3. Test for Significant Difference Between Groups

\begin{tabular}{|c|c|c|c|}
\hline Demographic Profile & Face-to-Face p-value & Blended Learning p-value & Full Online p-value \\
\hline Sex & 0.252 & 0.120 & 0.164 \\
\hline Number of Units & 0.126 & 0.808 & 0.824 \\
\hline Year Level & $0.001^{*}$ & $0.000^{*}$ & $0.001^{*}$ \\
\hline Number of Subjects & 0.249 & 0.860 & 0.842 \\
\hline
\end{tabular}

*Significant at .05 alpha level

Table above shows the test for significant difference between groups. This would mean that in each demographic profile, sub-levels were being compared (et.al. Male vs Female) across learning modalities (Face-to-Face Learning Modality, Blended Learning Modality, and Full Online Learning Modality).

For the sub-levels of Sex (male vs female), Number of Units (Above 20 and Below 20), and Number of subjects (more than 7 subjects, 6 to 7 subjects, and less than 6 subjects), the computed p-value is greater than .05 alpha level. This would mean that there is no significant difference in averages.

However, for Year level, the computed p-value is less than .05 across learning modalities. This would mean that there is significant difference in averages.

Table 4. Post Hoc Test for Year Level

\begin{tabular}{|c|c|c|c|}
\hline \multirow{2}{*}{ Learning Modality } & \multicolumn{3}{|c|}{ Year Level } \\
\cline { 2 - 4 } & First vs Second p-value & First vs Fourth p-value & Second vs Fourth p-value \\
\hline Face to Face & .631 & $.000^{*}$ & $.006^{\star}$ \\
\hline Blended & .238 & $.001^{*}$ & $.000^{\star}$ \\
\hline Full Online & .071 & $.020^{*}$ & $.000^{\star}$ \\
\hline
\end{tabular}

*Significant at .05 alpha level

Based on the Post Hoc Test, the computed p-value when Fourth Year Level is compared with First- and Second-Year Level is less than .05 alpha level. This would mean that there is significant difference. Hence, the average across different learning modalities for Fourth Year Level respondents is significantly lower compared to First- and Second-Year Level respondents.

\section{ANALYSIS AND DISCUSSIONS}

Based on the above results, Blended Learning Modality resulted to higher academic grade than Face-toFace Learning Modality. This would mean that, through Blended Learning Modality, academic performance based on average was significantly increase in comparison with Face-to-Face Learning Modality. In the 
same manner, Full Online Learning Modality resulted to higher academic grade than Face-to-Face Learning Modality. Academic Performance was significantly increase when Full Online Learning Modality was introduced to respondents in comparison with Face-to-Face Learning Modality.

Blended Learning Modality is not significantly different with Full Online Learning Modality. This would mean that Blended and Full Online Learning Modality increase more the academic performance that the traditional Face-to-Face Learning Modality.

Although the study found out that Blended Learning Modality and Full Online Learning Modality is better than Face-to-Face Learning Modality in terms of academic performance, the result that show any significant difference between sub-levels of each demographic profile across different learning modalities. This would mean that sex, number of units and subjects enrolled has nothing to do with learning modalities in increasing the academic performance.

However, the study found out that lower year respondents resulted significant higher academic performance across learning modalities (Face-to-Face Learning Modality, Blended Learning Modality and Full Online Learning Modality) than higher year respondents. This would mean that lower year levels perform better than higher year level across learning modalities.

Full Online Learning Modality is only the feasible strategy at this time of Pandemic due to social distancing policies as one of the mandated health protocols of the World Health Organization. Although, literatures and studies say that online learning modality is not of different with Face-to-Face Learning Modality when it comes to academic performance (Davies and Graff, 2005; Helms, 2014; Holley and Oliver, 2010; Imel, 2002; Otter et al., 2013; Chen and Zimitat, 2004; Paul, Jasmine et.al., 2019; Sussman \& Dutter 2010; and Van Schaik, Barker \& Beckstrand, 2003), the findings of the study supports that full-online learning modality is better and efficient compared with face-to-face learning modality (Ituma, 2011; Chen et al., 2010; Evans et al., 2004; Alismail, 2015; Robinson and Hullinger, 2008; Baskin, 2001; Salamat, et.al., 2018; and Stacey, 1999). Also, the results of the study support the findings of Paul, Jasmine et.al., (2019) that gender has nothing to with academic performance in Face-to-Face Learning Modality.

With this findings, Blended Learning Modality and Full Online Learning Modality can facilitate academic success to students in times of crisis or pandemic. Or even the absence of pandemic, considerable time and student's and pacing, self-directed learning by means of academic and learning independence can help students to achieve success in their academic performance. At the time of technological revolution, the pedagogical shift to online learning can be a good way to deliver education to our students.

\section{CONCLUSION}

Based on the conduct and results of the study, the researcher concluded that Blended Learning Modality and Face-To-Face Learning Modality is more effective in increasing academic performance than Face-to-FaceLearning Modality. And regardless whether blended or full-online learning modality, the study found out no significant difference in academic performance. Sex, number of units and subjects enrolled has nothing to do with a academic performance across different learning modalities. However, the findings of the study resulted to higher performance of lower year level than higher level across learning modalities.

\section{RECOMMENDATIONS}

The researcher recommends researchers to consider types of assessment, lived experiences and similar variables not included in this study as an opportunity for future research. They can also use comparison between learners' level of education as one of the possible analysis in the conduct of a research similar to this research.

\section{LIMITATIONS}

This study is limited only with the use of three learning modalities such as face-to-face, blended learning and full online. Academic performance is measured based on the weighted average of student per period (prelim, midterm, and finals). Comparative analysis was used to check significant difference across learning modalities and demographic profiles (sex, number of units, year level, and number of subjects). Anything not included in the study will be part of the limitations but can be recommended for future research.

\section{ACKNOWLEDGEMENT}

The researcher would like to acknowledge St. Dominic College of Asia for the financial and moral support in making this research be possible. To my colleagues under the Psychology Department and School of Arts, 
Sciences and Education, thank you for the unconditional love and support in my personal and professional career with the said institution. Special thanks to my family and my partner for being there in the success of this paper.

\section{REFERENCE LIST}

${ }^{1}$ Article entitled "Pandemic school closures: risks and opportunities". The Lancet Child \& Adolescent Health. Retrieved from https://www.thelancet.com/journals/lanchi/article/PIIS2352-4642(20)30105-X/fulltext.

${ }^{2}$ Article entitled "748 private schools suspend operations this school year, DepEd says". CNN Philippines. Retrieved from: https://www.cnnphilippines.com/news/2020/9/9/Private-schools-temporary-closureDepEd-.html

${ }^{3}$ Article entitled "Face-to-Face Learning". Retrieved from: https://www.colleges.co.za/face-to-face-learning

${ }^{4}$ Kemp, N., \& Grieve, R. (2014). Face-to-face or face to-screen? Undergraduates' opinions and test performance in classroom vs. Online learning. Vol. 5. Article 1278. Frontiers in Psychology. DOI: 10.3389/fpsyg.2014.01278

${ }^{5}$ Carini, R. M., Kuh, G. D., and Klein, S. P. (2006). Student engagement and student learning: testing the linkages. Res. High. Educ. 47, 1-29. doi: 10.1007/s11162-005-8150-9"

${ }^{6}$ Bonk, C., Kim, K., \& Zeng, T., (2006). Future directions of blended learning in higher education and workplace learning settings. In C. Bonk \& C. Graham (Eds). The handbook of blended learning: Global perspectives, local designs. Pfeiffer: San Francisco, 550-565

${ }^{7}$ Whitelock, D., \& Jelfs, A. (2003). Editorial for special issue on blended learning: blending the issues and concerns of staff and students. Journal of Educational Media, 28(2-3), 99-100

${ }^{8}$ Osguthorpe, R., \& Graham, C., (2003). Blended learning environments: Definitions and directions. Quarterly Review of Distance Education, 4(3), 227-233.

${ }^{9}$ Alismail, H. A. (2015). 21st Century Standards and Curriculum: Current Research and Practice. Journal of Education and Practice, 6(6), 150-155.

${ }^{10}$ Ituma, A. (2011). An evaluation of students' perceptions and engagement with e-learning components in a campus-based university. Active Learn. High. Educ.12, 57-68. doi: 10.1177/1469787410387722.

${ }^{11}$ Chen, P.-S., Lambert, A. D., and Guidry, K. R. (2010). Engaging online learners: the impact of web-based learning technology on college student engagement. Comput. Educ. 54, 1222-1232. doi: 10.1016/j.compedu.2009.11.008

${ }^{12}$ Evans, C., Gibbons, N. J., Shah, K., and Griffin, D. K. (2004). Virtual learning in the biological sciences: pitfalls of simply "putting notes on the web" Comput. Educ. 43, 49-61. doi: 10.1016/j.compedu.2003.12.004.

${ }^{13}$ Robinson, C. C., and Hullinger, H. (2008). New benchmarks in higher education: Student engagement in online learning. J. Educ. Bus. 84, 101-109. doi:10.3200/JOEB.84.2.101-109.

${ }^{14}$ Salamat, L., Ahmad, G., Bakht, I., \& Saifi, I. L. (2018). Effects of E-Learning on Students' Academic learning at university Level. Asian Innovative Journal of Social Sciences and Humanities, 2(2), 1-12.

${ }^{15}$ Baskin, C. (2001). The Titanic, Volkswagens and collaborative group work: Remaking old favourites with new learning technologies. Australasian Journal of Educational Technology 17(3), pp. 265-278.

${ }^{16}$ Stacey, E., \& Gerbic, P. (2006). Teaching for blended learning. How is ICT impacting on distance and on campus education? In D. Kumar \& J. Turner (Eds). Education for the 21 st century: Impact of ICT and digital resources. WCC 2006 Santiago, Chile. New York: Springer, 225-234.

${ }^{17}$ Alducin-Ochoa, Juan \& Vazquez-Martinez, Ana (2016). Academic Performance in Blended-Learning and Face-to-Face University Teaching. Asian Social Science.

${ }^{18}$ Ladyshewsky, R. (2004). E-learning compared with face-to-face: Differences in the academic achievement 
of postgraduate business students. Australasian Journal of Educational Technology, 20(3), 316-336.

${ }^{19}$ Davies, J., and Graff, M. (2005). Performance in e-learning: online participation and student grades. Br. J. Educ. Technol. 36, 657-663. doi: 10.1111/j.1467-8535.2005.00542.x.

${ }^{20}$ Holley, D., and Oliver, M. (2010). Student engagement and blended learning: portraits of risk. Comput. Educ. 54, 693-700. doi: 10.1016/j.compedu.2009.08.035

${ }^{21}$ Helms, Jeffrey L. (2014). Comparing Student Performance in Online and Face-to-Face Delivery Modalities. Journal of Asynchronous Learning Networks. Retrieved from: https://oli.onlinelearningconsortium.org/index.php/oli/article/view/348/93

${ }^{22}$ Imel, S. (2002). E-learning-Trends and Issues Alert. (Report No-40). Washington, DC: Office of Educational Research and Improvement.

${ }^{23}$ Otter, R. R., Seipel, S., Graeff, T., Alexander, B., Boraiko, C., Gray, J., et al. (2013). Comparing student and faculty perceptions of online and traditional courses. Internet High. Educ. 19, 27-35. doi: 10.1016/j.iheduc.2013.08.001

${ }^{24}$ Paul, Jasmine \& Jefferson, Felicia (2019). A Comparative Analysis of Student Performance in an Online vs. Face-to-Face Environmental Science Course From 2009 to 2016. Retrieved from: https://www.frontiersin.org/articles/10.3389/fcomp.2019.00007/full

${ }^{25}$ Sussman, Stephen \& Dutter Lee (2010). Comparing Student Learning Outcomes in Face-To-Face and Online Course Delivery. Retrieved from: https://www.westga.edu/ distance/ojdla/winter134/sussman dutter134.html

${ }^{26}$ Van Schaik, P., Barker, P., \& Beckstrand, S. (2003). Innovations in Education \& Teaching International, 40(1), 5-15.

${ }^{27}$ Chen, N., \& Zimitat, C. (2004). Differences in the quality of learning outcomes in a F2F blended versus wholly online course. Beyond the comfort zone: Proceedings of the $21^{\text {st }}$ ASCILITE Conference, Perth, 175-179. 